\section{Herbal anti-edematous agents for certain cases of facial cellulitis of odontogenic origin: clinical recommendation}

\section{Abstract}

Literature from different parts of the world reported that antibiotic abuse is evident in dental practice. One aspect of this abuse is prescribing antibiotics for non-indicated orofacial infections. The use of some herbal anti-edematous agents has been recommended for reducing post-operative swelling/edema in certain oral and maxillofacial surgical procedures. In this review we describe the possible benefits of using these agents for certain cases of facial cellulitis in order to reduce the number of antibiotic prescriptions for this particular clinical situation.

Keywords

Aescin; Antibiotics; Bromelain; Cellulitis; Dental; Edema; Herbal; Lips.

\section{Introduction}

Oral infections arise from different microbes that inhabit the oral cavity including viral, bacterial, and fungal microorganisms [1]. Bacterial oral infections are of major concern because their line of management may overlap with antibiotic prescribing and subsequently the possibility of antibiotic abuse may arise. Although indications for antibiotic prescribing in dental infections are well defined [2], recent literature still reports a high prevalence of antibiotic abuse in dental practice $[3,4]$. Facial cellulitis, is an infection in the soft tissues of the face that presents as diffuse, erythematous swelling, resulting from the spread of pathogenic bacteria which are typically Streptococci and Stapholococci. The severity of the infection is initially determined by virulence of invading bacteria and the host's response [5]. Associated swelling may worsen with time, with the area characterized by being warm, tender, and indurated. It may also be accompanied by fever
Najla Dar-Odeh',

Shaden Abu-Hammad²,

Osama Abu-Hammad ${ }^{1}$

1 Professor, College of Dentistry, Taibah University, Al Madinah Al Munawara,

Saudi Arabia, Amman, Jordan.

2 Student, School of Dentistry, University of Jordan, Amman, Jordan.

Contact information:

Najla Dar-Odeh.

Address: Professor, College of Dentistry, Taibah University, Al Madinah Al Munawara, Saudi Arabia and School of Dentistry, University of Jordan, Amman, Jordan.

झ najla_dar_odeh@yahoo.com 
Figure 1: Labial cellulitis associated with a periapical abscess (around tooth apex) related to upper central incisor (arrow). Courtesy of Dr Hamsa Sheera and Dr Arwa Jafar, Al Madina Saudi Arabia.

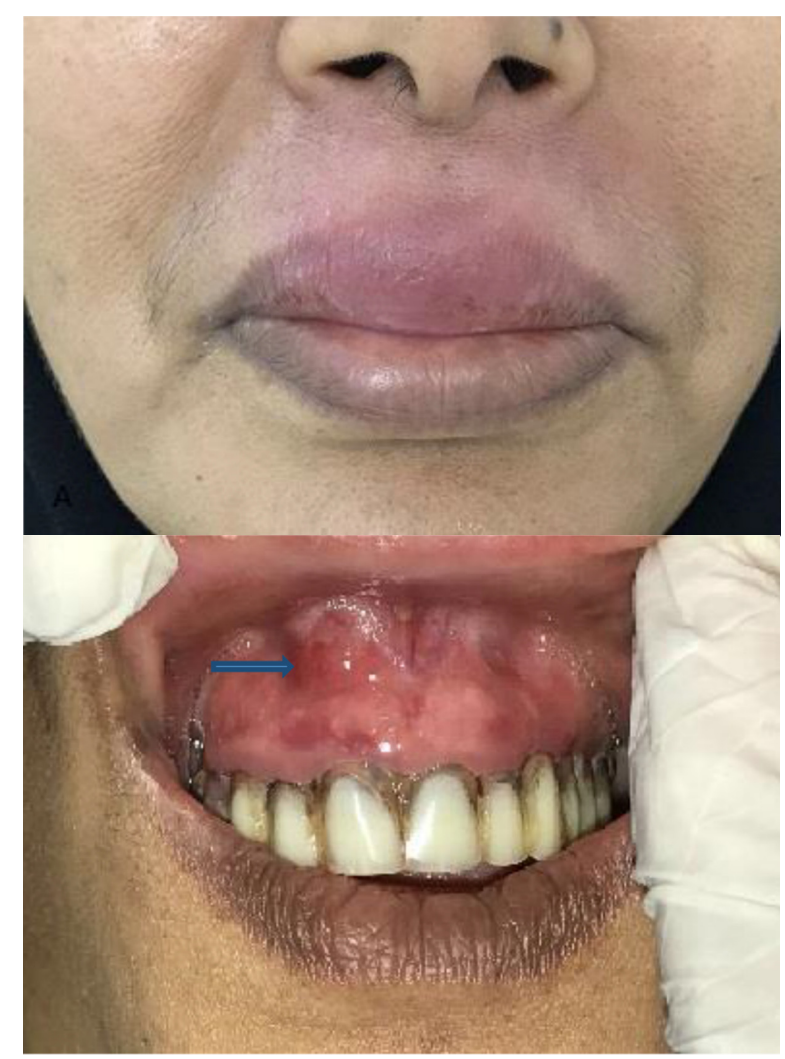

Figure 2: Lip cellulitis associated with odontogenic infection around a maxillary incisor. Courtesy of Dr Heba Alshaikh Ali, Amman, Jordan.

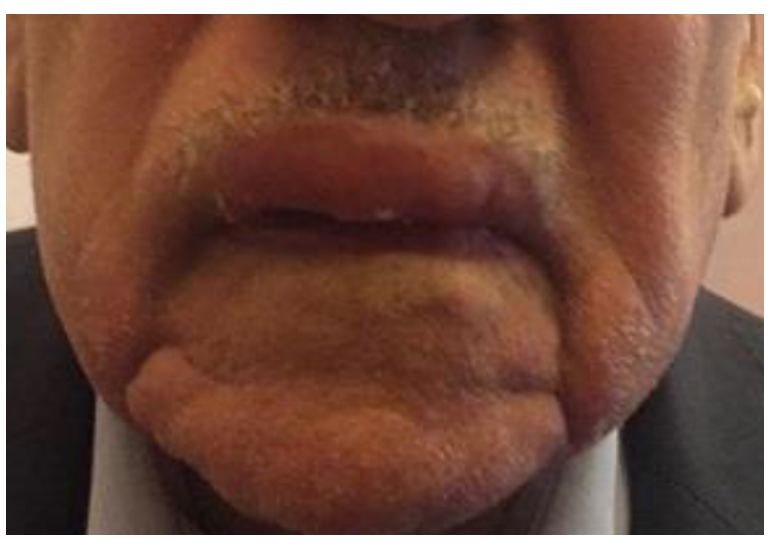

and lymphadenopathy. Arising from a dental infection on many occasions, it has been considered a classical indication for antibiotics in dental practice [6]. The recommendation is to use antibiotics as an adjunct to pus drainage as the initial management followed by removal of the source of infection at a later stage. Timely treatment is essential to prevent serious comorbidities associated with facial cellulitis [7].

A specific clinical scenario relates to chronic periapical infection associated with maxillary incisors that may spread to the upper lip causing a localized upper lip swelling, and here the upper lip becomes swollen, reddish and tender (Figures $1 \& 2$ ). In this particular case, a question arises as to whether an antibiotic prescription is required to supplement pus drainage. Another question arises as to whether alternative medications, that are not associated with the anticipated adverse effects of antibiotics, can be prescribed.

This mini review aims at exploring the potential use of anti-edematous herbal medications as the preferable adjunctive therapy to pus drainage in cellulitis affecting the upper lip.

\section{Methods}

A literature search was conducted in MEDLINE/PubMed, Web of Science, and Google Scholar databases using the following five combinations of MeSH Terms: herbal AND dental AND infection; Bromelain AND dental; Aescin AND dental; Aescin AND cellulitis; Bromelain AND cellulitis. Above search revealed no articles. Hence, it was decided to consider articles with the following two combinations of MeSH Terms: Oral surgery AND Aescin; Oral surgery AND bromelain.

The search was conducted up to and including October 2018. There was no time frame and only articles written in English were included. Search resulted in 11 articles and after exclusion of nonEnglish literature and animal studies, 5 articles re- 
sulted; 2 of them were irrelevant after review of abstracts and 3 investigated the efficacy of use of Bromelain after extraction of third molars to reduce postoperative discomfort [8-10].

\section{Results and Discussion}

Relevant articles reported only the use of Bromelain. However, Aescin has been reported to have the same advantages and is used either in chronic venous insufficiency or in the post-surgical period to reduce postoperative edema and swelling, so relevant literature on Aescin was included.

\section{Aescin}

Our search revealed that there are no studies investigating the effect of Aescin to reduce inflammation, swelling or edema in the orofacial region. However, it was important to include this herbal medication in our report to highlight its potential use in dental practice. $\beta$-Aescin is a mixture of triterpene saponins isolated from horse chestnut seeds (Aesculus hippocastanum, L.) [11]. Vascular efficacy of $\beta$-Aescinis attributed to improved microcirculation, reduced vascular permeability, increased venous tone and venous return, resulting in edema reduction [12]. This efficacy is attributed to the protective effects on endothelial cells from hypoxia and inflammatory stimuli [13], and to its modulatory effect on the TNF- $\alpha$-mediated inflammatory pathways [14]. It further affects endothelial cell structure and function by disrupting the actin cytoskeleton and decreasing expression of TNF- $\alpha$-induced effector proteins inducing disturbances of cholesterol homeostasis [11].

Capillary-stabilizing agents similar to Aescin have been used efficiently in some medical fields to reduce extravasation of fluid into the tissues thus encouraging edema to subside. Aescin has been recommended in the treatment of early stages of chronic venous insufficiency [15]. It is effective in reduction of skin reddening and cutaneous swelling as a result of effects on capillaries and their surrounding con- nective tissues [16]. Preparations containing Aescin have been proven to be safe with the presence of sporadic reports on transient gastrointestinal disorders [17]. As clearly indicated by all reported studies, it is generally well tolerated. Poisoning with horse chestnut seeds is attributed to the toxic esculoside component, not to Aescin [18]. The recommended daily dose of Aescin is $120 \mathrm{mg}$ divided into three daily doses.

\section{Bromelain}

It is interesting to find that Bromelain was the most commonly investigated herb in the field of oral surgery, if not the only one. It is one of a group of peptide hydrolases, all thiol proteinases, obtained from pineapple stems and fruit; orally administered in the treatment of inflammation and edema of soft tissues associated with traumatic injury. It appears to inhibit the production of pro-inflammatory prostaglandins, induce production of anti-inflammatory Series 1 prostaglandins, and reduce capillary permeability [19].

Bromelain has gained particular interest in plastic surgery because of its apparent anti-edematous, anti-inflammatory, and anticoagulation properties, which can be beneficial in postoperative healing, and it has been shown to be most effective when taken orally [20]. Most recent research on bromelain within dental practice was conducted in the past 5 years and was focused on the potential to reduce postoperative surgical sequelae of swelling and edema in dental extraction [8, 21, 22]. However, research on this herbal remedy was conducted initially throughout the 1960s and 1970s when a series of studies found that the effects of orally administered Bromelain included the reduction of edema, bruising, pain, and healing time following trauma and surgical procedures [23].

A recent systematic review reported that Bromelain was found to be effective at controlling postoperative pain at 48-72h after surgery, but did not achieve a significant effect with regard to edema 
[24]. An incidence of $1.8 \%$ of associated side effects is considered very low and it includes diarrhea, nausea, and allergic reaction [25]. When used in the perioperative period of surgery, the recommended dosing is $500 \mathrm{mg} 3$ times daily between meals beginning the day of surgery and continuing for 8 days [26].

It is obvious that the literature mentioned above have investigated the use of Aescin and Bromelain in applications other than dentistry. In dental practice Bromelain was mentioned for its potential effect in reducing postoperative edema after surgical extraction. Yet, a recent systematic review reported that Bromelain has no effect in reducing postoperative swelling [24]. This will lead to the next question; would a medication/herb that could have a potential in reducing postoperative edema, be also effective as an adjunct in the management of ceIlulitis? It is important in this report to point out to the possible differences in the spread of infection between various facial spaces.

In the upper labial region, the anatomic path of infection is attributed to the location of the roots of upper central incisors and upper lateral incisors which are in $50 \%$ of cases close to the labial surface, so the swelling would be limited by the attachment of the orbicularis oris, and the dense subcutaneous tissue at the base of the nose [27]. Infection caused by anterior teeth often spreads into the levator labii superioris and levator anguli oris muscles [28]. Appropriate clinical management for this condition necessitates drainage of pus depending on its location. This can be achieved by either root canal treatment, abscess drainage or tooth extraction if the tooth is not restorable.

Prescription of antibiotics should not be considered as part of first line treatment in these patients. We suggest that antibiotics would not necessarily be the first line of management; their use can be avoided/postponed and a modification can be done in this particular clinical scenario. Patients may actually benefit from drainage supplemented by a prescrip- tion of an anti-edematous agent. After achieving drainage and prescription of Aescin or Bromelain, the patient should be reviewed in 24-48 hours to assess response to treatment. If worsening of the condition is noticed or if there is no improvement, an antibiotic prescription can be considered.

We suggest the inclusion of Aescin and Bromelain in dental formularies so as to introduce it to the dental community and encourage dental practitioners to use it in the management of facial cellulitis of low-moderate severity, especially when drainage is feasible, and patient follow-up is closely performed. We also recommend that clinical trials on these preparations are conducted to judge their validity for use in relevant odontogenic infections.

\section{Acknowledgment}

Authors would like to thank Dr Heba Alshaikh Ali, Amman, Jordan, Dr Hamsa Sheera and Dr Arwa Jafar, Al Madina Saudi Arabia for providing the clinical pictures used in this report.

\section{References}

1. Dar-Odeh, Najla S, Al-Beyari M, Abu-Hammad OA. The role of antifungal drugs in the management of stomatitis. Int Arab J Antimicrob Agents 2012;2:1-5. doi:10.3823/705.

2. Dar-Odeh NS, Al-Abdalla M, Al-Shayyab MH, Obeidat $H$, Obeidat L, Kar MA, et al. Prescribing Antibiotics for pediatric dental patients in Jordan; knowledge and attitudes of dentists. Int Arab J Antimicrob Agents 2013;3:4. doi:10.3823/736.

3. Tomczyk S, Whitten T, Holzbauer SM LR. Combating antibiotic resistance: a survey on the antibiotic-prescribing habits of dentists. Gen Dent 2018;66:61-8.

4. Bird L, Landes D, Robson T, Sturrock A LJ. Higher antibiotic prescribing propensity of dentists in deprived areas and those with greater access to care in the North East and Cumbria, UK. Br Dent J 2018;225:517-24.

5. Greenstein, Gary, Greenstein B. Clinical Management of Acute Orofacial Infections. Compend Contin Educ Dent 2015;36:96103

6. Dar-Odeh N, Fadel HT, Abu-Hammad S, Abdeljawad R, AbuHammad OA. Antibiotic prescribing for Oro-facial infections in the paediatric outpatient: A review. Antibiotics 2018;7. doi:10.3390/antibiotics7020038. 
7. ipahi Calis A, Ozveri Koyuncu B, Ozturk K, Mert A BC. General approach to the treatment of odontogenic abscesses and cost analysis. J Istanb Univ Fac Dent 2015;49:17-22.

8. Majid OW, Al-Mashhadani BA. Perioperative bromelain reduces pain and swelling and improves quality of life measures after mandibular third molar surgery: A randomized, double-blind, placebo-controlled clinical trial. J Oral Maxillofac Surg 2014. doi:10.1016/j.joms.2013.12.035.

9. Singh T, More V, Fatima U, Karpe T, Aleem MA, Prameela J. Effect of proteolytic enzyme bromelain on pain and swelling after removal of third molars. J Int Soc Prev Community Dent 2016. doi:10.4103/2231-0762.197192.

10. Ghensi P, Cucchi A, Creminelli L, Tomasi C, Zavan B, Maiorana C. Effect of Oral Administration of Bromelain on Postoperative Discomfort after Third Molar Surgery. J Craniofac Surg 2017. doi:10.1097/SCS.0000000000003154.

11. Domanski D, Zegrocka-Stendel O, Perzanowska A, Dutkiewicz M, Kowalewska M, Grabowska I, et al. Molecular mechanism for cellular response to $\beta$-escin and its therapeutic implications. PLoS One 2016. doi:10.1371/journal.pone.0164365.

12. Tiffany $\mathrm{N}$, Boon $\mathrm{H}$, Ulbricht $\mathrm{C}$, Basch $\mathrm{E}$, Bent $\mathrm{S}$, Barrette $E P$, et al. Horse chestnut:a multidisciplinary clinical review. J Herb Pharmacother 2002.

13. Frick RW. Three treatments for chronic venous insufficiency: Escin, hydroxyethylrutoside, and Daflon. Angiology 2000. doi:10.1177/000331970005100303.

14. Gupta SC, Tyagi AK, Deshmukh-Taskar P, Hinojosa M, Prasad $S$, Aggarwal BB. Downregulation of tumor necrosis factor and other proinflammatory biomarkers by polyphenols. Arch Biochem Biophys 2014. doi:10.1016/j.abb.2014.06.006.

15. Ottillinger B, Greeske K. Rational therapy of chronic venous insufficiency - Chances and limits of the therapeutic use of horse-chestnut seeds extract. BMC Cardiovasc Disord 2001. doi:10.1186/1471-2261-1-5.

16. Wilkinson JA, Brown AMG. Horse chestnut - Aesculus hippocastanum: Potential applications in cosmetic skincare products. Int J Cosmet Sci 1999. doi:10.1046/j.14672494.1999.234192.x.

17. Dudek-Makuch M, Studzińska-Sroka E. Horse chestnut - efficacy and safety in chronic venous insufficiency: an overview. Rev Bras Farmacogn 2015. doi:10.1016/j.bjp.2015.05.009

18. Bayer G. Martindale: The Complete Drug Reference. 38th ed. Aust Prescr 2015. doi:10.18773/austprescr.2015.023.

19. Taussig SJ. The mechanism of the physiological action of bromelain. Med Hypotheses 1980. doi:10.1016/03069877(80)90038-9.

20. Orsini RA. Bromelain. Plast Reconstr Surg 2006. doi:10.1097/01. prs.0000242503.50548.ee.

21. Ordesi P, Pisoni L, Nannei P, Macchi M, Borloni R, Siervo S. Therapeutic efficacy of bromelain in impacted third molar surgery: A randomized controlled clinical study. Quintessence Int (Berl) 2014. doi:10.3290/j.qi.a32237.
22. Bormann KH, Weber $K$, Kloppenburg $H$, Koch $A$, Meiser $P$, Gellrich NC. Perioperative Bromelain Therapy after Wisdom Teeth Extraction - A Randomized, Placebo-Controlled, DoubleBlinded, Three-Armed, Cross-Over Dose-Finding Study. Phyther Res 2016. doi:10.1002/ptr.5707.

23. Zatuchni GI, Colombi DJ. Bromelains therapy for the prevention of episiotomy pain. Obstet Gynecol 1967.

24. de R, de Sousa Lima FCM, do BC. Is bromelain an effective drug for the control of pain and inflammation associated with impacted third molar surgery? Systematic review and meta-analysis. Int J Oral Maxillofac Surg 2018. doi:10.1016/j. ijom.2018.07.028.

25. Maurer HR. Bromelain: Biochemistry, pharmacology and medical use. Cell Mol Life Sci 2001. doi:10.1007/PL00000936.

26. Reddy KK, Grossman L, Rogers GS. Common complementary and alternative therapies with potential use in dermatologic surgery: Risks and benefits. J Am Acad Dermatol 2013. doi:10.1016/j.jaad.2011.06.030.

27. Morse DR. Oral Pathways of Infection. Int Endod J 1972. doi:10.1111/j.1365-2591.1972.tb00064.x.

28. Obayashi N, Ariji Y, Goto M, Izumi M, Naitoh M, Kurita K, et al. Spread of odontogenic infection originating in the maxillary teeth: Computerized tomographic assessment. Oral Surgery, Oral Med Oral Pathol Oral Radiol Endodontology 2004. doi:10.1016/j.tripleo.2004.05.014.

\section{Publish in The International}

Arabic Journal of Antimicrobial Agents

The Journal is an open access peer-reviewed journal that publishes scientific papers about all aspects of antimicrobials. The journal will publish original research articles, reviews, brief reports and case reports dealing with basic and clinical antibacterial agents, antiviral, antiprotozoals, antituberculuous, antifungal and antihelminthes agents. All manuscripts must be prepared in English, and are subject to a rigorous and fair peer-review process. Accepted papers will immediately appear online. The journal aims to advance the knowledge, attitude and the research of chemotherapy in the Arabic world in cooperation with international, national scientific and public societies as well as research centers with similar aims and objectives. 